\title{
ОСНОВНЫЕ НАПРАВЛЕНИЯ РЕАЛИЗАЦИИ ИНКЛЮЗИВНОГО ОБУЧЕНИЯ В ОРГАНИЗАЦИЯХ, ПРЕДОСТАВЛЯЮЩИХ УСЛУГИ ОСНОВНОГО ОБЩЕГО ОБРАЗОВАНИЯ НА ТЕРРИТОРИИ КРАСНОЯРСКОГО КРАЯ
}

\author{
(c) 2019 Белецкий Максим Джамалуддинович \\ кандидат экономических наук, доцент кафедры Экономической теории и менеджмента \\ Московский педагогический государственный университет, Россия, Москва \\ E-mail: beletsky.maksim@yandex.ru \\ (C) 2019 Крупецких Игорь Ростиславович \\ студент 4-го курса кафедры Экономической теории и менеджмента \\ Московский педагогический государственный университет, Россия, Москва \\ E-mail: krupetskikh@yandex.ru
}

Потребность в получении знаний, раскрытии собственного потенциала и интеграции в социум - неотъемлемые элементы гармоничного развития личности, независимо от особенностей конкретного индивида. В настоящее время властями реализуется концепции безбарьерной среды для «исключительных детей», но, несмотря на усилия государства, дети, имеющие инвалидность, все еще встречают препятствия к социализации, значимую роль в которой играет образование.

Ключевые слова: дети с ограниченными возможностями здоровья, инклюзивное образовательное пространство, основное общее образование, педагогические технологии, политика Министерства образования, Концепция о развитии инклюзивного образования в Красноярском крае, Федеральная государственная информационная система «Федеральный реестр инвалидов».

В настоящее время инклюзивное образование играет ключевую роль в организации образовательных процессов для всех обучающихся, вне зависимости от состояния их здоровья. Отношение Министерства образования и науки РФ к данному виду образовательных услуг выражается в предоставлении методических рекомендаций по организации образовательного процесса для обучения инвалидов и лиц с ограниченными возможностями здоровья в образовательных организациях на всех ступенях образования, в том числе относительно оснащенности образовательного процесса [4], датированными 2014 г. и содержащими основную компетентностную парадигму, суть которой состоит в создании так называемого «включающего образования», позволяющего детям всех возрастов, независимо от пола, возраста, этнической принадлежности, способностей, наличия или отсутствия нарушений развития и ВИЧ-инфекции, участвовать в жизни общества и вносить в нее свой вклад.

B XXI веке наблюдается рост численности инвалидов из года в год, что подтверждают многочисленные статистические данные разных источников, в том числе и официальный сайт Федеральной государственной информационной системы «Федеральный реестр инвалидов» [9] (далее - ФГИС ФРИ). Согласно данным ФГИС ФРИ, численность детей-инвалидов по Российской Федерации на 01.01.2019 составляет 670086 чел., среди которых $43 \%$ девочки и $57 \%$ мальчики. Примечательно то, что эта цифра составляет лишь 5,3\% от общей численности инвалидов по России. Для наглядности представим данные о количестве детей-инвалидов по возрастным группам на рис. 1.

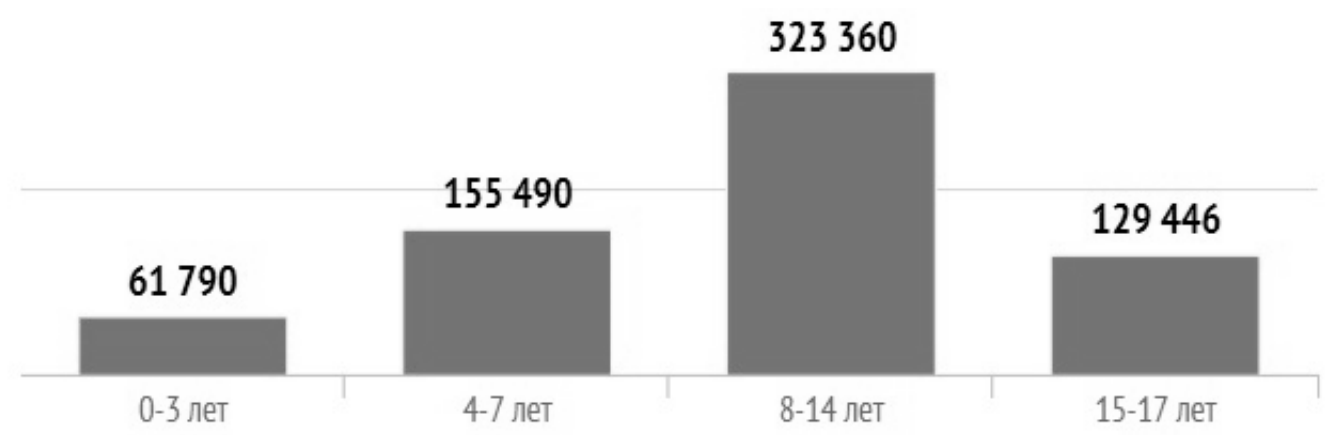

Рuc. 1. Численность детей-инвалидов на территории РФ по возрастным группам 
Как видно из рис. 1, большинство детей с ограниченными возможностями здоровья относятся к возрастной категории от 8 до 14 лет (323360 чел.). Данная группа детей (8-14 лет) не случайно выделена обособлено и не разделена на подгруппы, это сделано для того, чтобы сделать акцент на проблеме обеспечения образовательными организациями инклюзивного образования на основном общем этапе, к нуждающимся в котором относится самая многочисленная возрастная группа детей с ограниченными возможностями здоровья.

Исследованием организации инклюзивного образовательного процесса на всех ступенях образования, в частности на ступени основного общего образования, занимаются многие зарубежные и отечественные исследователи, в частности: Н.В. Тамарская, М.Д. Белецкий, Д.З. Ахметова, В.В. Хитрюк, Ж.Л. Клейман, Т.М. Париева, И.Н. Трущенко, С.В.Шандыбо и др.

Проблема качества управления системой современного российского образования является актуальной, поскольку стремительно изменяющиеся социально-экономические условия, постоянное реформирование содержания образовательных стандартов, а также развитие субъектов образовательного процесса провоцируют не только потребность в преобразовании этой системы как на уровне образовательной организации, так и на уровне государственного регулирования, но и решение такой важнейшей задачи, как гуманизация условий жизнедеятельности людей и общества в целом посредством предоставления возможностей для развития способностей, внутренней душевной целостности, граничащих с жизнестойкостью с жизнеспособностью. Решение данной задачи необходимо находить своевременно, в особенности, когда речь идет о людях с ограниченными возможностями.

Сопоставительный анализ педагогических управленческих технологий, применяемых на западе и в Российской Федерации, позволяет подтвердить большую вариативность этих технологий в зарубежной практике в сравнении с отечественной, т.к. для зарубежной образовательной системы, по мнению Н.В. Тамарской, характерно наличие более расширенного круга субъектов инклюзивного обучения, что обосновывает более целенаправленное регулирование управление инклюзивным образование, чем в практике современной российской образовательной системы [7; с. 487].

В условиях современной рыночной экономики множество образовательных организаций по всей России проявляют неподдельный интерес к проблемам внедрения инклюзивного образования. Связано это, по мнению М.Д. Белецкого, с тем, что использование такого инструмента как инклюзия на всех уровнях образования для людей с ограниченными возможностями здоровья является одной из наиболее эффективных мер, способствующих ликвидации безнравственной практики обособления детей-инвалидов, а также инвалидов других возрастных групп в том числе и от образовательного процесса [2, с. 17].

ИсследователямиА.В. Челюкановой,Н.А. Ельниковой, И.Ю. Лебеденко выделены следующие направления организации инклюзивного образовательно процесса в школе, в частности:

- постоянное снабжение школ интерактивными технологиями, используя которые, обучающийся с ограничениями возможностями способен стать частью флуктуирующих субъектно-объективных взаимоотношений обучающей системы образования и стать их полноправным активным участником;

- непрерывное внедрение дистанционных технологий в систему школьного образования, позволяющее формирование общедоступности образовательных услуг независимо от места и от времени;

- повсеместное оборудование в школах пандусов, лифтов, поручней, перилл, контрастной маркировки, а также специальных информационных стендов [11, с. 98].

К вышеперечисленным подходам к организации инклюзивного обучения в образовательных учреждениях, предоставляющих услуги основного общего образования, также можно отнести проектирование зданий, предполагающих наличие приемлемой ширины проходов как между столами (партами) для обучающихся, передвигающихся на специальных опорах и в креслах-колясках - не менее 0,9 м; между рядом столов (парт) и стеной с оконными проемами не менее 0,5 м; между рядами столов и стенами без оконных проемов - не менее 1,0 м; пространство между столами (партами) в рядах не менее 0,85 м. Данные нормы представлены в Разделе 4 «Здания и помещения учебно-воспитательного значения» свода правил общественных зданий и сооружений, доступным ма- 
ломобильным группам населения, требования к проектированию которых утверждены Приказом Федерального агентства по строительству и жилищно-коммунальному хозяйству 27 декабря 2012 г. [6].

Образовательным организациям, предоставляющим услуги основного общего образования, необходимо, по мнению Д.З. Ахметовой, целостно и пошагово решать ряд таких задач в области инклюзивного образования, как:

- создание удобоваримой безбарьерной среды инклюзивного образовательного процесса;

- подготовка рабочих мест для обучающихся с максимальным учётом специфики их «исключительности»;

- организация переподготовки преподавательского состава образовательного учреждения, с целью формирования у учителей культуры толерантности, а также навыков фасилитации, которые были определены исследователями Ж.Л. Клейман, Т.М. Париевой, И.Н. Трущенко как способ стимулирования партнерских отношений между обучающим и обучающимся, основной задачей которых является развитие стремления к получению знаний по тому или иному предмету и разъяснение конечной цели получения образования на той или иной ступени [3, с. 46];

- проведение предварительных бесед как с родителями, так и с обучающимися о концепции и специфике инклюзивного образования, а также о гуманности данного процесса;

- снабжение образовательной организации такими квалифицированными кадрами как медицинский работник, социальный педагог, педагог-психолог, педагогические тьюторы и т.д. (количество и состав вспомогательных специалистов в данном случае определяется самой образовательной организацией как правило в содействии с медико-психологической комиссией) [1, с. 45].
Поступенчатое решение образовательными организациями заявленных выше задач способствует формированию благоприятного инклюзивного образовательного пространства для детей с ограниченными возможностями здоровья. Под инклюзивным образовательным пространством исследователь В.В. Хитрюк понимает такую интегративную единицу социального пространства, в которой для каждого участника в посильном формате происходит реализация межличностных и образовательных взаимоотношений, гарантирующих как личностное, так и социальное развитие, а также социализацию индивида вкупе с его саморазвитием и самоизменениями [10, с. 33].

Рассматривая систему организации инклюзивного обучения в школах в Красноярском крае с целью оценки эффективности политики местных органов образования в исследуемом направлении, ознакомимся со статистикой по численности детей-инвалидов на территории вышеупомянутого региона, исходя из данных, предоставленных ФГИС ФРИ на 01.01.2019 [9]. Согласно сведениям Федерального реестра инвалидов, на территории Красноярского края проживает 12873 чел. детей-инвалидов, среди которых 41\% девочки и 59\% мальчики. Данный показатель составляет 18,3\% от общей численности инвалидов, проживающих в регионе. Для наглядности представим данные о количестве детей-инвалидов по возрастным группам на рис. 2.

Из рис. 2 следует, в Красноярском крае основное число детей-инвалидов, как и по всей России, приходится на возрастную группу от 8 до 14 лет. Выбор данного специфического метода классификации возрастных групп детей-инвалидов был обоснован нами ранее.

Следует принять во внимание то, что в Красноярском крае в настоящее время активно реализуются программы инклюзивного и специального образования на основном общем

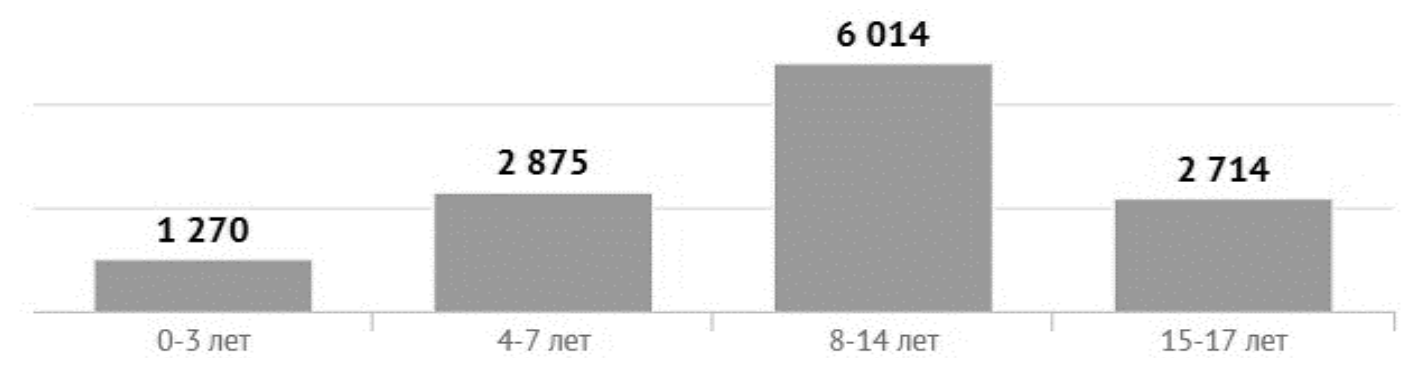

Puc. 2. Численность детей-инвалидов на территории Красноярского края по возрастным группам 
этапе. Инициативность политики Министерства образования Красноярского края в данном направлении, по мнению С.В.Шандыбо, обусловлена во многом «хорошей» историей введения инклюзивного образования на всех уровнях образовательно вертикали и тем, что первая концепция специального образования датируется 2003 г. [12, с. 3].

В настоящее время Концепция развития инклюзивного образования в Красноярском крае, которая была утверждена указом губернатором края от 13.10.2017 № 258-УГ [8], представляет из себя систему положений о получении образования детьми, имеющими языковые, этнические, возрастные, интеллектуальные, социальные, гигиенические и другие особенности, в том числе и детьми-инвалидами. Данная Концепция призвана раскрыть цели, задачи и принципы совершенствования инклюзивного образования, а также определить основополагающие направления и способы реализации образовательной политики на региональном уровне в сфере образования детей с ограниченными возможностями здоровья.

На сегодняшний день программы инклю- зивного образования в Красноярском крае реализуются в 813 общеобразовательных учреждениях для 6682 детей-инвалидов, что составляет $36 \%$ от общего числа «исключительных» детей школьного возраста. Также, по статистике, представленной на официальном сайте Министерства образования Красноярского края, образовательные программы инклюзивного образования реализуются в отдельных классах муниципальных школ [5].

Проанализировав статистику по количеству детей-инвалидов на территории РФ, статистику по их количеству в Красноярском крае, разграничив при этом данные показатели на рис. 1 и на рис. 2 по возрастному признаку, а также проведя изучение основных положений Концепции развития инклюзивного образования на территории исследуемого региона, можно сделать вывод о том, что прослеживается определенная динамика в области совершенствования так называемого «включающего образования», создания удобоваримой безбарьерной среды инклюзивного образовательного процесса и благоприятного инклюзивного образовательного пространства.

\section{Библиографический список}

1. Ахметова Д.З. Идеи концепции непрерывного инклюзивного образования // КНЖ. - 2014. - № 1 (6). - С. 44-45.

2. Белецкий М.Д. Ключевые аспекты проблемы трудоустройства инвалидов в России // Ежемесячный научный журнал «Дискуссия» - «7 (81)».- 2017.- С. 16-21.

3. Клейман Ж.Л., Париева Т.М., Трущенко И.Н. Значение и роль вузовского педагога-фасилитатора // Наука 21 века: вопросы, гипотезы, ответы - № 2 (11) - 2015.- С. 46-49.

4. Методические рекомендации по организации образовательного процесса для обучения инвалидов и лиц с ограниченными возможностями здоровья в образовательных организациях высшего образования, в том числе оснащенности образовательного процесса: утв. Министерством образования и науки РФ 8 апреля 2014 г. № AK-44/05вн. Режим доступа: https://base.garant.ru/70680520/, свободный.

5. Официальный сайт Министерства образования Красноярского края. Режим доступа: http://www.krao.ru/ deyatelnost/obrazovanie-detej-s-ovz-i-invalidnostyu/inklyuzivnoe-i-spetsialnoe-obrazovanie/, свободный.

6. Свод правил общественные здания и сооружения, доступные маломобильным группам населения. Правила проектирования. (Утвержден Приказом Федерального агентства по строительству и жилищно-коммунальному хозяйству от 27 декабря 2012 г. N124/ГC). Режим доступа: http://mtsk.mos.ru/Handlers/Files.ashx/ Download? ID=19399, свободный.

7. Тамарская Н.В. Особенности управления инклюзивным образованием в образовательной организации / Научный альманах. Педагогические науки. - № 7 (9) - 2015.- С. 487-490.

8. Указ Губернатора Красноярского края от 13 октября 2017 г. 2ㅏ일 «Об утверждении Концепции развития инклюзивного образования в Красноярском крае на 2017-2025 годы» (с изменениями и дополнениями). Режим доступа: http://www.krao.ru/media/editor/uploads/2018/08/03/258-ug.pdf, свободный.

9. Федеральная государственная информационная система «Федеральный реестр инвалидов». Режим доступа: https://sfri.ru, свободный.

10. Хитрюк В.В. Инклюзивное образовательное пространство: SWOT-анализ / В.В. Хитрюк, И.Н. Симаева // Вестник Балтийского федерального университета имени И. Канта.- Вып. 5. - 2014. - С. 31-39. 
11. Челюканова А.В., Ельникова Н.А., Лебеденко И.Ю. Современные технологии инклюзивного образования в краснодарском крае / Центр научного сотрудничества «Интерактив плюс».— № 2 (8) - 2016. - С. 97-100.

12. Шандыбо С.В. Практика развития инклюзивного образования в Красноярском крае: специфика, принципы, задачи//ежеквартальный информационный журнал для общественно-активных школ.- Красноярск, «Сотрудничество».- № 2-3.- 2016.- С. 3-20. 